\title{
Vecinos en conflicto: ¿un dilema ético?
}

\author{
El hombre de al lado | M. Cohn y G. Duprat | 2009 \\ Ana Irene Medina* y Mirta Carrasco** \\ Facultad de Química, Bioquímica y Farmacia, Universidad Nacional de San Luis, Argentina
}

Recibido: 1 de noviembre 2016; aceptado: 29 de junio 2017

\begin{abstract}
Resumen
El hombre de al lado es una película dirigida por Mariano Cohn y Gastón Duprat Argentina y estrenada en el año 2009. A partir del hecho de la apertura de una ventana en una pared que comparten dos vecinos, se pone en juego la interacción entre personas pertenecientes a distintos campos sociales. El problema se convierte en un conflicto y el conflicto en un dilema ético que intenta distintas formas de resolución. En el discurrir de la película se van desenmascarando los verdaderos valores de los protagonistas como representantes de los campos sociales de los cuales provienen. Se analizan las acciones bajo posturas ético-filosóficas deontológicas, desde Kant, Habermas hasta Cortina.
\end{abstract}

Palabras clave: conflicto | dilema ético | bioética | moral

Neighbors in conflict: an ethical dilemma?

\begin{abstract}
The house next door is a film directed by Mariano Cohn and Gastón Duprat Argentina and premiered in 2009.From the fact of opening a window in a wall shared by two neighbors, it is put into play the interaction between people from different social fields. The problem becomes a conflict and conflict in an ethical dilemma trying different ways of resolution. The problem becomes a conflict and conflict in an ethical dilemma trying different ways of resolution. In the flow of the film they will unmaskthe true values of the protagonists as representatives of the social fields which come. Actions under deontological ethical-philosophical positions are analyzed, from Kant, Habermas to Cortina.
\end{abstract}

Key words: conflict | ethical dilemma | bioethics | moral

Desde la consagrada mirada indiscreta de James Stewart en 1954, la ventana, como objeto, logra simbolizar la capacidad intrusiva e intimidante de la observación; como un medio que nos permite conocer otra realidad, descubrir personas y mundos antagónicos (Barbaro,2010). El hombre de al lado, es una película argentina de Mariano Cohn y Gastón Duprat, estrenada en 2009, que recrea esta vieja idea de la indiscreción curiosa entre personas. A partir de este hecho, logra reflejar a una sociedad que, dividida por muros sociales y culturales, teme mirar al otro y diferenciar los verdaderos valores del ser humano. Obtuvo un premio a la mejor fotografía en el Festival de Sundance 2010 y el premio de mejor película argentina en el Festival de Mar de Plata 2009.

Con el sonido ensordecedor de martillazos rompiendo una pared, sorprenden dos imágenes simultáneas dividiendo la pantalla en dos caras contrapuestas que muestran la apertura de un hueco en la pared. De esta manera, los directores, desde la primera escena de la película instalan en los espectadores una historia con dos miradas antagónicas de una misma comunidad vecinal.

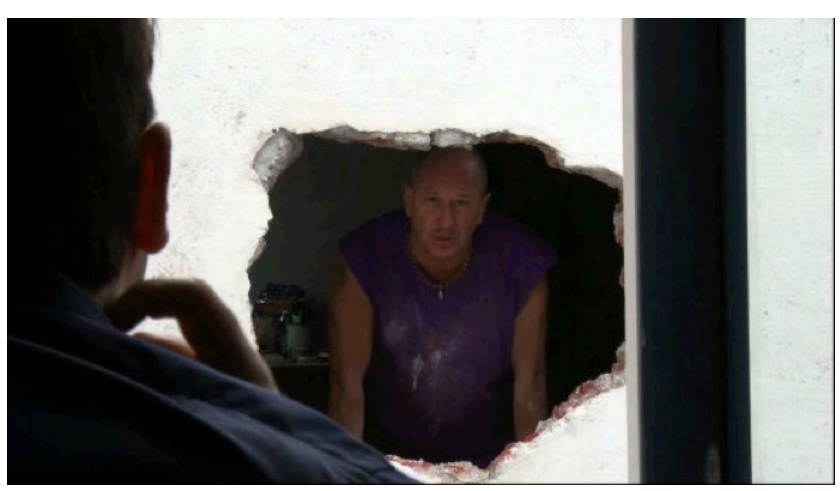


Víctor, uno de los protagonistas de la película, intenta hacer una ventana en la medianera que comparte con su vecino Leonardo, el otro protagonista. A partir de este hecho tan simple como provocador se pone en juego la armonía de la convivencia entre vecinos y surge el conflicto. Esa ventana se trasforma en un objeto simbólico de intromisión e intimidación sobre Leonardo y su familia, constituida por su esposa e hija.

La trama de la película se desarrolla en un barrio de clase media alta con la interacción de dos vecinos que supuestamente pertenecen a una misma clase social. Leonardo es arquitecto, exitoso profesor universitario, diseña muebles específicamente sillas, habla varios idiomas, pertenece a una clase social alta, se comunica con el mundo exterior, social y laboral, mediante modernas herramientas tecnológicas, su imagen profesional se detalla cuidadosamente en una página Web muy estudiada mediante entrevistas televisivas. Representa claramente a un intelectual burgués, sofisticado que alardea de sus actos y está muy seguro del lugar social que ocupa. No casualmente, vive junto a su familia en una propiedad emblemática de la ciudad de La Plata: la casa Curutchet. ${ }^{1}$ La casa es visitada diariamente por estudiantes de arquitectura, transeúntes y turistas, es decir que Leonardo convive con la exposición diaria de la casa a extraños, curiosos, etc. Es así que se lo ve al mismísimo Leonardo, en varias oportunidades, disfrutar de esas visitas con toques de buen humor, siempre y cuando esté todo bajo control.

En contraste, Víctor es llano, directo, emocional, espontáneo y auténtico. La única propiedad que muestra es su camioneta negra, su interior presenta una decoración exagerada, kitsch. No se sabe en qué trabaja y vive con su tío con capacidades diferentes. Muestra un vocabulario vulgar y un comportamiento un tanto grotesco, se desenvuelve sin prejuicios, es avasallante, seguro de sí mismo, pero en comparación con Leonardo, Víctor aparece como un personaje menos educado perteneciente a una clase social más baja.

Así los personajes caracterizados, representan mundos sociales distintos, que varían según su posición y sería natural inferir que ambos manifiestan distintos \habitus $\bigotimes$ en cuanto a que las prácticas sociales, incorporadas inconscientemente a lo largo de las historias de cada personaje, manifiestan diferencias en la percepción, las acciones y el pensamiento, esto es producto de la internalización de las estructuras sociales(Bourdieu, 1988). En la película se define un campo social donde está en juego el capital social que según Bourdieu es el
“... conjunto de los recursos actuales o potenciales que están ligados a la posesión de una red durable de relaciones más o menos institucionalizadas de inter-conocimiento y de inter-reconocimiento; o, en otros términos, a la pertenencia a un grupo, como conjunto de agentes que no sólo están dotados de propiedades comunes (susceptibles de ser percibidas por el observador, por los otros o por ellos mismos), sino que también están unidos por lazos permanentes y útiles" (Gutiérrez, 1997).

Así a través del "habitus", tenemos un mundo de sentido común, un mundo social que parece evidente y nos permite identificar a Víctor con menor capital social, cultural y simbólico en comparación con el capital acumulado de Leonardo. Si establecemos como capital simbólico aquel que se ha adquirido por el reconocimiento del entorno social e institucional, por ejemplo, en este caso el título universitario que posee Leonardo le da el prestigio y un reconocimiento social. Según Bourdieu (1988), los títulos académicos, representan verdaderos títulos de propiedad simbólica que dan derecho a ventajas de reconocimiento, establecen y garantizan oficialmente los rangos conocidos y reconocidos universalmente.

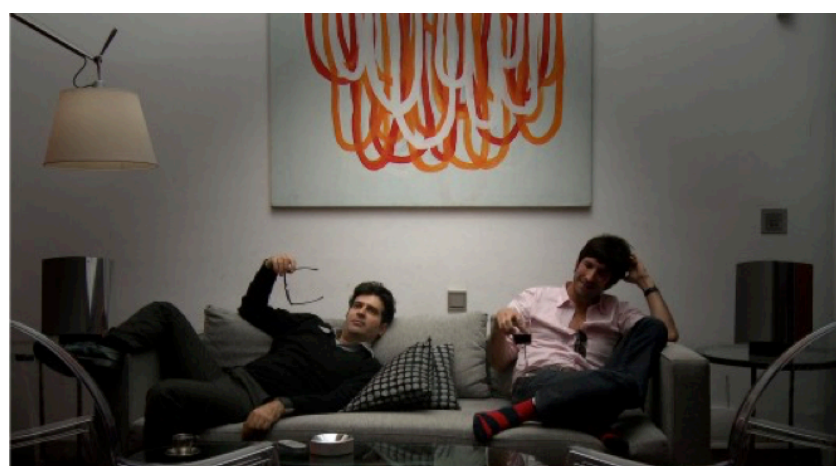

El capital bourdiano del que hablamos, es un capital de relaciones mundanas que se pone en evidencia entre Víctor y Leonardo desde sus posiciones en el campo social. Ambos pujan por obtener un rédito diferencial de capital simbólico (fuerza ejercida por los protagonistas para poner en valor lo que en ese campo está en juego), con estrategias que responden al estilo de vida, que en cada uno funciona con diferentes cantidades, por así decirlo, de capital legitimado, en la hegemonía, del entorno social. Se establece una lucha de poder que no se percibe como tal sino como exigencia de reconocimiento, obediencia, entre uno y otro personaje.

Al centrarnos en los personajes, Víctor (el otro) responde a un estilo de vida totalmente diferente al de Leonardo. La diferencia entre las posiciones sociales a las que pertenecen Víctor y Leonardo, se basa en la acumulación y distribución del capital específico que está en juego en ese campo. 


\section{Conflicto: leyes morales (Víctor) vs. leyes escritas (Leonardo)}

Es importante tener en cuenta que el foco de la cámara está casi siempre sobre Leonardo y su entorno por lo que la dinámica de la película se desarrolla desde la visualización del problema que Leonardo debe resolver.

Víctor inicia el problema mencionado al abrir la ventana para "captar unos rayitos de sol”, además, no se lo plantea como un generador de conflicto, debido a que la casa de Leonardo es, por un lado, públicamente visitada a diario por su importancia arquitectónica y, por otro lado, presenta grandes ventanales que permiten la visión desde las muchísimas otras ventanas del edificio de enfrente. A partir de allí se inician procesos que, por su desarrollo y las metodologías utilizadas para gestionarlos, conllevan resultados que pueden profundizar la crisis y/o generar cambios en la relación de vecinos que obstaculicen un consenso.

Víctor avanza con la apertura del hueco en la pared acompañado de una invasión sonora, molesta. Leonardo, busca asesoramiento en su entorno social, con abogados y profesionales inmobiliarios. Va elucubrando estrategias que intentará imponer a su vecino, Víctor, como únicas posibles de solución. Sin embargo, Víctor insiste en el encuentro personal, en el acercamiento, en el diálogo, mientras espía a través del hueco en la pared a su vecino Leonardo y su familia.

Hay dos escenas, donde se pone de manifiesto la sensibilidad de Víctor en contraste con la indiferencia de Leonardo. En primer lugar, la hija de Leonardo está caracterizada como una adolescente que tiene problemas de comunicación, especialmente con su padre, y que transcurre la mayor parte del tiempo con auriculares, escuchando música aislada del resto de los integrantes de la casa. Leonardo llega un día a su casa e intenta establecer un diálogo con ella, hablándole desde cierta distancia y detrás de una puerta. En esta escena asistimos a un monólogo tipo interrogatorio, casi cómico, mientras la niña no abandona nunca los auriculares, no escucha ni una palabra de lo que dice su padre, asimismo, Leonardo no registra la indiferencia que genera en su hija. Por el contrario, hay una puesta en escena, casi tierna, donde Víctor del otro lado del hueco (futura ventana), representa una obra de teatro con música, haciendo uso simplemente de sus manos disfrazadas con restos de alimentos en una simpática escenografía y coreografía, un tanto grotesca, pero llena de imaginación creativa, que deja sonrientes a la niña y al público. Especialmente este último, experimenta una distensión en esta carrera por convencer el uno al otro de sus propios intereses. Durante toda la película se visualiza fuertemente el poder como variable del conflicto, ya que tanto Leonardo como Víctor utilizan el poder para direccionar, lo más rápidamente posible, el resultado del conflicto favorable a sus propios intereses, uno para resistir con la decisión tomada (apertura de la ventana en la medianera) y el otro, por su complejidad de intelectual burgués, para convencerlo a través de cualquier método (dentro y fuera de la ley).

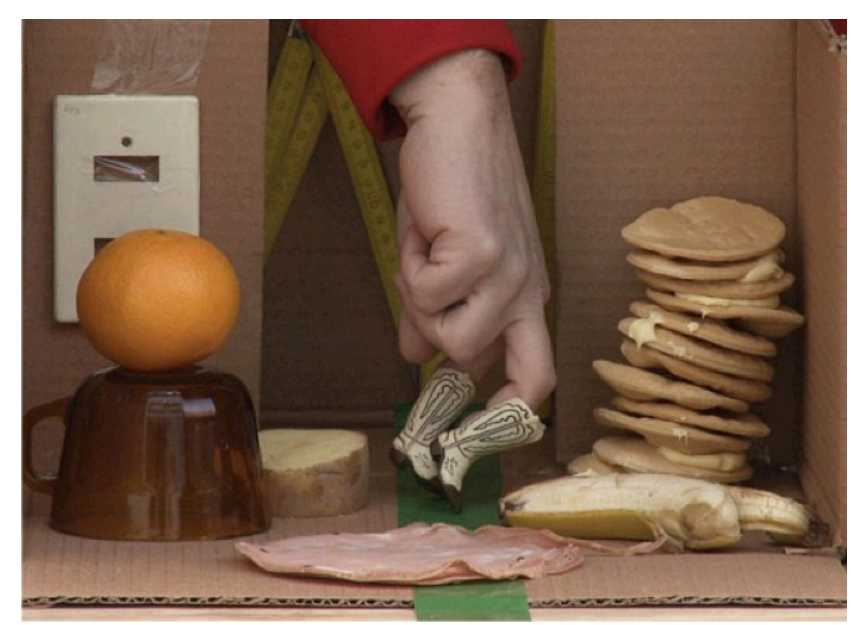

Es Víctor el que busca el diálogo, aunque justifica su acción basado en fundamentos alejados de la racionalidad, esto es una manera de actuar sin pensar, sin siquiera contemplar la ley, sólo lo motiva la necesidad personal y doméstica de tener luz, y desde el sentido común da por sentada la aceptación de su vecino. Pero, es en este personaje que uno vislumbra una racionalidad comunicativa, en el sentido que propone Habermas (1998), porque Víctor va en busca de un entendimiento lingüístico, asumiendo sin saberlo que comparten un mismo código entre los dos, convencido de que será posible llegar a un acuerdo. Habermas (1998) dice:

“...el concepto de acción comunicativa se refiere a la interacción de al menos dos sujetos capaces de lenguaje y de acción que (ya sea con medios verbales o con medios extra verbales) entablan una relación interpersonal El concepto aquí central, el de interpretación, se refiere primordialmente a la negociación de definiciones de la situación susceptibles de consenso. En este modelo de acción el lenguaje ocupa, como veremos, un puesto prominente..."

Si bien el lenguaje tiene un rol central en la búsqueda de consenso como modo de resolución de conflictos, es necesario que los individuos racionales, que inician una acción conjunta de diálogo cumplan con lo que señala Habermas (1998): 
“...los participantes en la interacción se ponen de acuerdo acerca de la validez que pretenden para sus emisiones o manifestaciones, es decir, que reconocen intersubjetivamente las pretensiones de validez con que se presentan unos frente a otros..."

Es decir, que entre dos sujetos que pretenden resolver un conflicto existe la necesidad, para que esto sea factible, que se reconozcan como interlocutores válidos, como sujetos racionales que actúan de buena fe en busca de una solución al problema. Solo cuando existe una igual consideración para con el otro, uno puede permitir la crítica de sus enunciados, pero en este caso esto no sucede. Es Leonardo, quien menosprecia a su vecino, se burla de sus acciones y de sus acercamientos (frente a su esposa, amigos, familia) y, detesta su sola presencia. Además, utiliza permanentemente la mentira como instrumento para quedar bien, para cubrir su cobardía o para librarse de Víctor. En este sentido, la mentira hace moralmente inaceptable una racionalidad comunicativa, no pudiendo perder de vista lo señalado por Habermas (1998) respecto de las pretensiones de validez:

“...El hablante pretende, pues, verdad para los enunciados o para las presuposiciones de existencia, rectitud para las acciones legítimamente reguladas y para el contexto normativo de éstas, y veracidad para la manifestación de sus vivencias subjetivas..."

Por esta misma razón, es imposible resolver este conflicto que se va trasformando a lo largo de la película en un dilema ético en la mente de los espectadores. Los directores, van mostrando los aspectos comportamentales de los protagonistas poniendo al público en el dilema de tomar una posición entre uno u otro de los personajes.

\section{Intuiciones morales y toma de posición final}

El desenlace de la película muestra claramente quién es quién en la toma de decisión ante un hecho trágico: el robo. Víctor demuestra actitud positiva frente a la situación cuando frustra el robo que se comete en la casa de su vecino. Es en esa acción cuando lo hieren de muerte, situación que aprovecha Leonardo, quién nunca estuvo interesado en Víctor como persona, para precipitar la resolución del conflicto, dejándolo morir. Sin embargo, Víctor actúa conforme al deber al enfrentar a los ladrones en la casa de su vecino. Según Kant, es un acto moralmente bueno porque se procede según el deber sin inclinación alguna, esto es, en la conciencia moral de Víctor rige un imperativo categórico (no conoce condiciones) que lo lleva a obrar según el principio subjetivo del acto. En cambio, Leonardo decide (con premeditación) no salvar a su vecino porque no le conviene, entonces actúa por inclinación y no por deber.

La última escena, desgarradora por cierto, termina con el juego que ha llevado al límite del espectador, que acorralado no tiene manera de escapar y deberá tomar una posición final del tipo: ¿de qué lado estás?. En esta parte asistimos a un despliegue de valores morales como la solidaridad, la valentía que impulsan a Víctor a socorrer a sus vecinos. Es casi imposible que el espectador no se sienta identificado con el acto heroico y desinteresado de Víctor, y repudie internamente la actitud egoísta, insensible e inhumana de Leonardo.

Anteriormente destacamos el capital simbólico que poseía Leonardo teniendo en cuenta la propiedad cultural y educativa, sin embargo, Bourdieu (1997) señala que el capital simbólico:

“...es cualquier propiedad (cualquier tipo de capital, físico, económico, cultural, social) cuando es percibida por agentes sociales cuyas categorías de percepción son de tal naturaleza que les permite conocerla (distinguirla) y reconocerla, conferirle algún valor.”

Aquí hacemos un nuevo análisis que nos cambia la mirada sobre Víctor, otorgándole un mayor capital simbólico, en comparación con su vecino Leonardo que habiendo recibido más educación y reconocimiento social, su egocentrismo individualista lo imposibilita a reconocer al otro (Víctor), como a un ser humano igual que él, y por eso puede dejarlo morir, bajo su mirada vigilante. Y el espectador aquí, queda paralizado emocionalmente ante la presencia de semejante acción, mientras procesa en su mente, lo que siente con el corazón.

En el marco de la ética kantiana, las acciones del sujeto están determinadas por la racionalidad junto con las emociones (amor, odio, orgullo, placer, etc.) que influyen sobre las mismas. Asimismo, Cortina (2010) profundiza esta idea y cierra un círculo en la misma línea de la ética deontológica kantiana cuando propone la ética de la razón cordial. Esta ética además de fundamentarse y de dotarse de una herramienta en la búsqueda de la verdad, debe apuntalarse en las razones del corazón que son las que nos van a crear un vínculo imprescindible entre lo que debemos y queremos hacer, un vínculo en el reconocimiento recíproco y en la lealtad entre los seres que son fines en sí mismos (Sanchéz Pachón, 2015). Leonardo instrumentaliza la vida de Víctor, usándola como un medio para obtener un fin, el fin al conflicto. Sus emociones, su sensibilidad, su corazón, parecen remontarse a tiempos medievales en que dominaban las ideas aristoté- 
licas. Alli la vida de una persona no valía nada si pertenecía a una clase social baja, que al igual que un animal no poseía alma y por lo tanto podía ser esclavizada.

Si reflexionamos sobre los comportamientos antagónicos de los personajes en El hombre de al lado, no podemos evitar emitir juicios morales que inevitablemente van asociados con sentimientos. En esta misma dirección reflexiva, y en sintonía con la ética comunicativa habermessiana, Maturana (1989) señala que el surgimiento del lenguaje en la historia evolutiva humana, nace en el ámbito operacional de la aceptación mutua (amor) entre los primates, y lo verdaderamente humano queda fundado constitutivamente con la participación básica del emocionar y en particular del amor que da como resultado lo que él llama el conversar.

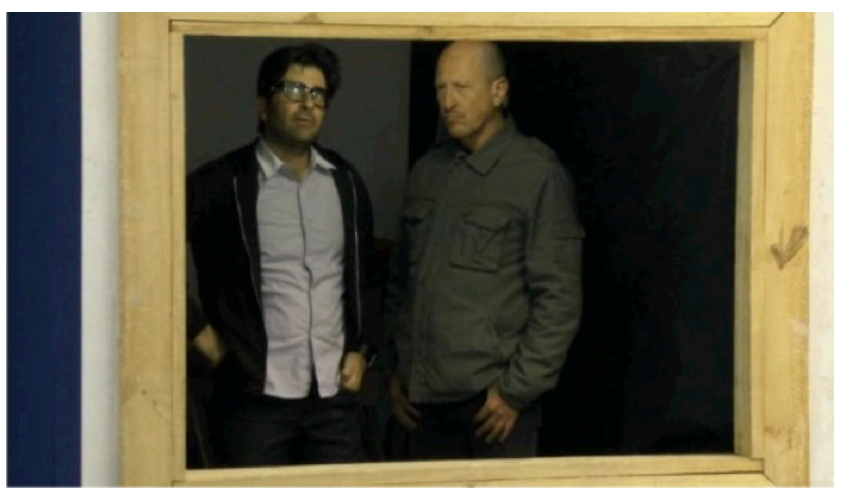

Es interesante tener en cuenta que los realizadores direccionan al público a ocupar el mismo lugar de
Leonardo, en cuanto no sabemos nada de Víctor más allá de lo que ve Leonardo. Esta situación hace que el público reflexione acerca de lo que haría ante la intromisión de un/unos extraños en su apacible y complaciente vida. ¿El no saber nada del otro, como le ocurre a Leonardo, generaría temor y ansiedad? Indudablemente que sí, entonces cabe la pregunta: ¿cómo buscar la cordialidad para llegar a una ética de la convivencia?

Según Cortina (2010), la ética de la razón cordial, ligada a las exigencias de la justicia, se inscribe en el paradigma del "reconocimiento recíproco", en donde la intersubjetividad humana se salvaguarda de cualquier daño; pero agrupa igualmente las riquezas de diversas tradiciones éticas: ética del discurso, en donde se estiman la competencia comunicativa y la capacidad de estimar valores; la ética kantiana, de donde se estima el valor de la persona como fin en sí mismo y el sentimiento de humanidad que no es otra cosa que la vivencia del móvil moral de la compasión por el sufrimiento.

En definitiva, para resolver un conflicto entre personas de una misma comunidad, debemos centrarnos en tres conceptos: 1) empatía que nos define como seres animales sociales, 2) aceptación mutua que nos permite encontrar la posibilidad del lenguaje en un contexto biológico-evolutivo y 3 ) reconocimiento recíproco, paradigma ético donde la intersubjetividad humana se salvvaguarda de cualquier daño.

\section{Referencias}

Aguayo P. W. 2011. Reseña: Cortina Adela. Justicia Cordial. Rev. Idea y Valores. Vol. 60 (147) 235-240.

Bourdieu P. 1988. Cosas dichas. Editorial Gedisa. Argentina.

Bourdieu P. 1997. Razones prácticas: sobre la teoría de la acción. Editorial Anagrama. Barcelona, España.

Cortina A. 2010.Justicia Cordial. Editorial Trotta. Madrid, España.

Habermas J. 1998. Teoría de la acción comunicativa I: Racionalidad de la acción y racionalización social. Ed. Taurus Humanidades. España.

Gutiérrez A. 1997. Pierre Bourdieu. Las prácticas sociales. Editorial Universitaria Universidad Nacional de Misiones. Argentina.

Maturana R. H. 1989. Lenguaje y realidad: origen de lo humano. Revista Colombiana de Psicología. Nos. 5-6: 200-203.

Sanchéz Pachón J. 2015. Adela Cortina: el reto de la ética cordial. Brocar, 39: 397-422.

Barbaro Marcela, 2010. El espectador imaginario. ISSN 2013438X

\footnotetext{
1 Diseñada por el arquitecto suizo Le Corbusier (entre 1949-1953), declarada de interés provincial, turístico y Monumento Histórico Nacional en 1987. Actualmente es sede del Colegio de Arquitectos de La Plata.
} 